\title{
IMPORTÂNCIA DE ANTICORPOS ANTI-MICA PRÉ-FORMADOS PARA A SOBREVIDA DO ENXERTO RENAL DE DOADOR FALECIDO
}

\author{
Clinical relevance of preformed anti-mica antibodies for survival of kidney graft from \\ deceased donor
}

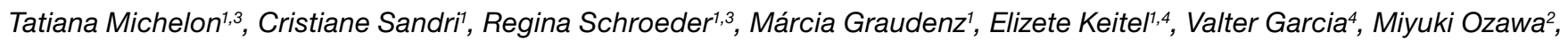
Paul Terasaki², Jorge Neumann ${ }^{3}$
\end{abstract}

\begin{abstract}
RESUMO
Introdução: Anticorpos anti-HLA pré-formados ou desenvolvidos após o transplante estão associados à menor sobrevida do enxerto. A importância de anticorpos contra aloantígenos MICA ainda não é clara. Objetivo: Determinar a prevalência de anticorpos anti-MICA pré-transplante em receptores de rim de doador falecido e analisar seu efeito na sobrevida do enxerto. Pacientes e Métodos: Foram estudados 339 transplantes renais de doador falecido realizados após prova cruzada negativa contra linfócitos T+AGH e B. A pesquisa de anticorpos anti-MICA foi realizada através de tecnologia Luminex, categorizada como: negativa (Neg, n=251; 74\%), fraco-positiva (FP, n=39; 11,5\%) e positiva (Pos, $n=49 ; 14,5 \%)$. Foram comparadas as características clínicas e do transplante (qui-quadrado, Fisher, t Student, Mann-Whitney), conforme o padrão sorológico para MICA. A sobrevida atuarial do enxerto foi analisada em modelo de cox-regression, incluindo os seguintes fatores: idade, sexo, teste de PRA pré-transplante, re-transplante, uso de terapia de indução e imunossupressão incluindo rapamicina, micofenolato mofetil e/ou tacrolimo x tríplice convencional (CyA+Aza+Pred). P<0,05 e IC95\%. Resultados: A prevalência de anticorpos anti-MICA pré-formados foi de 26\% (n=88). Pacientes anti-MICA positivos eram mais jovens (36,9+12,0 x 44,1+12,8anos; $\mathrm{P}=0,00)$, recebendo mais freqüentemente re-transplante $(20,4 \% \times 7,6 \%$; $\mathrm{P}=0,01$ ). O padrão sorológico anti-MICA pré-transplante não atingiu significância estatística para a sobrevida do enxerto (Negativo: HR=1; Fraco Positivo: $\mathrm{HR}=0,71 ; \mathrm{P}=0,25$; Positivo: $\mathrm{HR}=0,94 ; \mathrm{P}=0,88$ ); todavia, um efeito deletério moderado não pode ser excluído entre os receptores de um primeiro transplante (Fraco Positivo: HR=1,4[0,8-2,7], $\mathrm{P}=0,28$ e Positivo: $\mathrm{HR}=1,6[0,9-3,1], \mathrm{P}=0,14$ ). Nesse grupo, a intensidade da sensibilização anti-MICA demonstrou tendência linear (Ptrend=0,09). Conclusão: A prevalência de anticorpos anti-MICA pré-formados em transplante renal de doador falecido foi de $26 \%$, mais freqüente entre jovens recebendo re-transplante. Um efeito deletério na sobrevida do enxerto renal não pode ser excluído entre receptores de um primeiro enxerto, necessitando estudos com maior número de pacientes.
\end{abstract}

Descritores: Anticorpos, Mica, Transplante Renal, Sobrevivência de Enxerto.

\section{Instituições:}

1 Programa de Pós-Graduação em Patologia - Fundação Faculdade Federal de Ciências Médicas de Porto Alegre, Porto Alegre / RS - Brasil

2 Terasaki Foundation Laboratory, Los Angeles, CA - USA

${ }^{3}$ Santa Casa de Porto Alegre - Laboratório de Imunologia de Transplantes, Porto Alegre / RS - Brasil

${ }^{4}$ Santa Casa de Porto Alegre - Serviço de Transplante Renal, Porto Alegre / RS - Brasil

Correspondência:

Tatiana Michelon

Hospital Dom Vicente Scherer

Av. Independência, 75 - CEP 94035-075 - Porto Alegre / RS - Brasil

Tel/Fax: (51) 32148670 / (51) 32148629

E-mail: tatimich@yahoo.com

Fontes de auxílio à pesquisa:

- CAPES: programa PRODOC

- CNPq: programa BIC

- Terasaki Foundation Laboratory

Conflito de Interesse:

Paul Terasaki; acionista majoritário do Terasaki Foundation Laboratory

\section{INTRODUÇÃO}

A profilaxia da rejeição hiperaguda, através da realização de prova cruzada contra linfócitos de doador pré-transplante, e a profilaxia e tratamento eficaz dos eventos de rejeição celular com fármacos imunossupressores possibilitaram uma importante redução da morbidade associada aos transplantes de rim. ${ }^{1,2}$ No entanto, somente na última década vêm se desenvolvendo as possibilidades de profilaxia e de diagnóstico específico de eventos humorais no período pós-transplante precoce e tardio., Rejeições mediadas por anticorpo determinam menor sobrevida do enxerto e costumam ser irreversíveis, a menos que diagnosticadas muito precocemente e tratadas eficientemente com protocolos especiais, incluindo imunoglobulina humana endovenosa e plasmaferese. . $^{3,4,5,6}$

O diagnóstico de eventos humorais em transplante depende de ferramentas específicas, tais como a identificação de aloanticorpos e a demonstração de depósitos do subproduto C4d no endotélio de capilares peritubulares., ${ }^{7,89}$ Os anticorpos anti-HLA pré-formados, ainda que em baixos títulos, hoje são valorizados não apenas em transplante renal. ${ }^{10}$ Seu potencial deletério já foi também demonstrado 
em transplantes de coração, pulmão e pâncreas. ${ }^{11}$ Anticorpos anti-HLA formados após a exposição ao enxerto também ganharam importância no acompanhamento em longo prazo, após a demonstração de que estão associados à menor sobrevida do enxerto, podendo ser identificados na circulação periférica até mesmo anos antes da perda do enxerto. ${ }^{11,12}$

Além das moléculas HLA funcionando como aloantígenos em transplante, na última década, foram descritos os genes que codificam outras proteínas similares aos produtos de genes HLA de classe I. Essas moléculas apresentam uma distribuição peculiar, e são conhecidos como "marcadores de estresse". Os genes que as codificam também possuem moderado polimorfismo, apresentam co-dominância e localizam-se na região do HLA de classe I no cromossomo 6; porém, não são associadas a beta2-microglobulina e não apresentam peptídeo. ${ }^{13-15}$ Por possuírem essas características, foram denominadas "MIC", uma contração de "MHC Class I Chain-related". ${ }^{16}$

Estudos de mapeamento já identificaram sete loci MIC (MICAMICG), dos quais os loci MICA e MICB são os mais estudados. Mais de 60 alelos MICA e 30 alelos MICB foram identificados até o momento. Por tratar-se de um sistema polimórfico e seus produtos serem expressos por células endoteliais, monócitos e linfócitos T ativados (além de fibroblastos, queratinócitos, epitélio do trato gastrointestinal e células trofoblásticas), suspeita-se que moléculas MIC possam estar envolvidas em processos de rejeição em transplantes. ${ }^{15,16}$

O presente estudo tem como objetivo determinar a prevalência de pacientes submetidos a transplante renal com doador falecido em nosso meio com anticorpos anti-MICA pré-formados e analisar seu efeito na sobrevida do enxerto.

\section{PACIENTES E MÉTODOS}

Todos os transplantes renais com doador falecido realizados na Santa Casa de Porto Alegre entre Janeiro de 1998 e Dezembro de 2003 foram alocados para o presente estudo $(n=404)$, sendo excluídos $(\mathrm{n}=65 ; 16,1 \%)$ : a) receptores pediátricos $(\mathrm{n}=30)$, b) ausência de alíquota do soro testado no pré-transplante para os estudos propostos $(n=13)$ e c) ausência de células congeladas do doador $(n=12)$ por impedir sua inclusão em estudos complementares posteriores. Todos os pacientes assinaram um termo de consentimento livre e esclarecido no momento da sua internação para a realização do transplante e estudos laboratoriais pertinentes.

Os 339 receptores incluídos no estudo foram acompanhados desde a realização do transplante até dezembro de 2007 (1791_997 dias). Todos foram submetidos a transplante renal após prova cruzada negativa por técnica de citotoxicidade dependente de complemento, com adição de anti-globulina humana e ditiotreitol (CDC-AGH-DTT) contra linfócitos T e CDC-DTT contra linfócitos $\mathrm{B}$, realizados conforme recomendações da Associação Americana de Histocompatibilidade e Imunogenética (American Society for Histocompatibility and Immunogenetics -ASHI). A avaliação da reatividade contra painel (PRA) pré-transplante foi realizada através de técnica de imunoensaio enzimático (ELISA, screening LAT-M, One Lambda Inc., Canoga Park, CA, USA). O soro considerado positivo na avaliação de triagem por ELISA foi submetido à análise quantitativa através de citometria de fluxo (PRA-LS1, OneLambda Inc., Canoga Park, CA, USA). Neste último caso, foram considerados positivos os soros com reatividade $>10 \%$ e hipersensibilizados os receptores com reatividade maior ou igual a 75\% dos antígenos HLA testados. Ambas as técnicas empregadas para PRA avaliaram apenas a presença de anticorpos dirigidos contra moléculas HLA de classe I.

As análises para determinação dos anticorpos anti-MICA e suas respectivas especificidades foram realizadas por Tecnologia Luminex em uma alíquota do mesmo soro testado na prova cruzada CDC, imediatamente antes da realização do transplante e estocado a -800C. Foram determinados os níveis e as especificidades antigênicas dos anticorpos anti-MICA. Todos os soros passaram por triagem inicial quanto à presença ou ausência de anticorpos anti-MICA, utilizando kit Labscreen Mixed ${ }^{\circledR}$ (LSM12; One Lambda Inc., Canoga Park, CA, USA). Os casos positivos foram reavaliados através do kit Labscreen MICA Single Antigen (One Lambda Inc., Canoga Park, CA, USA) para detecção de anticorpos contra o painel, incluindo os seguintes antígenos MICA: *001, *002, *004, *007, *009, *012, $* 017$, *018, *019 e *027. Esse kit utiliza micro-pérolas revestidas com antígenos MICA purificados para detecção de anticorpos específicos presentes no soro. Empregou-se o Sistema de Ensaio Lambda Multi-analítico de Pérolas (LABMAS - Lambda Array Beads Multi-Analyte System) com analisador de fluxo LABscan 100 para aquisição de dados e análise.

Após a determinação dos níveis de anticorpos anti-MICA de acordo com o valor de fluorescência obtido, os soros foram categorizados para cada especificidade antigênica testada da seguinte forma: negativo (<1500); fraco-positivo (1500 a 2999) e positivo (>3000). O paciente, conforme a reatividade mais alta no painel de antígenos testados foi classificado como: negativo ( $\mathrm{Neg}, \mathrm{n}=251$; 74\%); fracopositivo (FP, $n=39 ; 11,5 \%$ ) ou positivo (Pos, $n=49 ; 14,5 \%$ ).

Os grupos FP e Pos foram comparados, respectivamente, ao grupo Neg para as características clínicas dos pacientes e do transplante e para a função e sobrevida atuarial do enxerto. Empregaram-se os testes de qui-quadrado ou exato de Fisher, t de Student ou Mann Whitney. Para a análise de efeitos na sobrevida do enxerto, aplicouse um modelo de Cox-regression incluindo os seguintes fatores: idade do receptor, gênero, resultado do PRA, uso de terapia de indução e imunossupressão empregando drogas de segunda ou terceira geração (micofenolato mofetil [MMF], tacrolimo [FK] e/ou rapamicina [rapa]) comparados ao esquema tríplice convencional (ciclosporina+azatioprina+prednisona, CyA+Aza+Pred). Foram considerados significativos os valores de $\mathrm{P}<0,05$ e intervalo de confiança de $95 \%$ (IC95\%).

\section{RESULTADOS}

A prevalência de pacientes submetidos a transplante com anticorpos anti-MICA pré-formados foi de $26 \%(n=88)$, apresentando as respectivas especificidades isoladas ou associadas: 7,6\% anti-001 ( $n=28) ; 3,8 \%$ anti-002 ( $n=13) ; 2,7 \%$ anti-004 $(n=9) ; 5,0 \%$ anti-007 $(\mathrm{n}=17) ; 11,5 \%$ anti-009 ( $\mathrm{n}=39), 4,4 \%$ anti-012 $(\mathrm{n}=15) ; 3,6 \%$ anti-017 $(\mathrm{n}=12) ; 4,1 \%$ anti-018 ( $\mathrm{n}=14) ; 8,9 \%$ anti-019 $(\mathrm{n}=30), 9,4 \%$ anti-027 $(n=32)$. A distribuição de freqüência conforme a intensidade de fluorescência para anticorpos anti-MICA estudados encontra-se descrita na Tabela 1.

$\mathrm{Na}$ amostra estudada, os pacientes Pos eram mais jovens (Neg : 44,1 $\pm 12,8$ x Pos:36,9 $\pm 12,0$ anos, $\mathrm{P}=0,00$ ) e recebiam mais frequentemente re-transplante (Neg :7,6\% x Pos :20,4\%, P=0,01, $\mathrm{OR}=3,1[1,4-7,2])$. Não houve diferença na distribuição de gêneros entre os grupos estudados (masculino, $n=182,53,7 \%$ ) e no 
Tabela 1. Distribuição da freqüência de anticorpos anti-MICA pré-formados em receptores de rim proveniente de doador falecido, conforme as respectivas especificidades antigênicas e intensidade de fluorescência.

\begin{tabular}{ccccc}
\hline $\begin{array}{c}\text { Especificidades } \\
\text { MICA }\end{array}$ & $\begin{array}{c}\text { Fraco } \\
\text { Positivo } \\
\mathbf{N}\end{array}$ & $\begin{array}{c}\text { Positivo } \\
\mathbf{n}\end{array}$ & $\mathbf{n}$ & $\mathbf{\%}$ \\
\hline 009 & 20 & 19 & 39 & 11,5 \\
027 & 13 & 19 & 32 & 9,4 \\
019 & 6 & 24 & 30 & 8,9 \\
001 & 12 & 14 & 26 & 7,6 \\
007 & 7 & 10 & 17 & 5,0 \\
012 & 4 & 11 & 15 & 4,4 \\
018 & 4 & 10 & 14 & 4,1 \\
002 & 3 & 10 & 13 & 3,8 \\
017 & 5 & 7 & 12 & 3,6 \\
004 & 4 & 5 & 9 & 2,7 \\
\hline Total & 39 & 49 & 88 & 26,0 \\
\hline
\end{tabular}

tempo médio de isquemia fria (20,8+5,7 horas). Também foram semelhantes as prevalências de PRA positivo ( $n=46,13,6 \%)$, de pacientes hipersensibilizados $(n=23,6,8 \%)$ e de transplantes combinados (rim+outro órgão sólido, $n=29,8,6 \%$ ). A Tabela 2 descreve as características dos pacientes e sua avaliação imunológica pré-transplante, conforme a presença de anticorpo anti-MICA pré-formado.

A terapia imunossupressora de indução com anticorpo anti-receptor de IL-2, quimérico ou humanizado foi utilizada com a mesma freqüência entre os grupos (Neg : 44,2\%, FP:46,2\% e Pos :36,7\%). $\mathrm{Na}$ análise do esquema imunossupressor inicial, pacientes antiMICA positivos receberam menos frequentemente a combinação de drogas mais modernas, como MMF, FK e/ou Rapa (n=22; 44,9\%, $\mathrm{P}=0,01, \mathrm{OR}=0,4[0,2-0,8])$ do que pacientes $\mathrm{Neg}(\mathrm{n}=164 ; 65,3 \%)$. O mesmo foi observado na comparação entre Pos e FP ( $n=22 ; 56,4 \%$, $\mathrm{P}=0,27)$, sem significância estatística. A descrição do esquema imunossupressor inicial encontra-se detalhada na Tabela 3. Os casos de re-transplantes, independente da terapia de indução e da pré-sensibilização contra antígenos MICA, receberam mais freqüentemente esquemas iniciais que incluíam drogas de segunda ou terceira geração ( $1^{\circ}$ transplante: 59,5\%; re-transplante: $81,8 \%$; $\mathrm{P}=0,02 ; \mathrm{OR}=3,1[1,2-7,6])$.

A função renal medida através da creatinina sérica no terceiro e sexto meses e, subsequentemente, com freqüência anual foi semelhante entre os grupos estudados ao longo do acompanhamento. A necessidade de diálise na primeira semana pós-transplante foi semelhante entre os grupos (192/314; 61,1\%) e a taxa de não-função primária do enxerto foi respectivamente de $2,8 \%(n=7), 5,1 \%(n=2)$ e $8,2 \%(n=4)$ entre os pacientes Neg*, FP $\left(P^{*}=0,34\right)$ e Pos $\left(P^{*}=0,08\right.$; $\mathrm{OR}=3,1[0,9-11,0])$.

A sobrevida atuarial do enxerto no período estudado (1998 a 2007) foi semelhante entre os grupos (Neg: $\mathrm{HR}=1,0 ; \mathrm{FP}: \mathrm{HR}=0,7, \mathrm{P}=0,25$; Pos:HR=0,94, $\mathrm{P}=0,88$ ). A Figura 1 apresenta as curvas de sobrevida aplicadas ao modelo de Cox-regression para pacientes submetidos ao primeiro transplante. O número pequeno de re-transplantes
Tabela 2. Descrição das características dos pacientes e dos fatores de risco imunológico pré-transplante entre receptores de rim, conforme a presença de anticorpos anti-MICA pré-formados.

\begin{tabular}{|c|c|c|c|}
\hline $\begin{array}{l}\text { Características } \\
\text { Pré-Transplante }\end{array}$ & $\begin{array}{c}\text { Anti-MICA } \\
\text { Negativo }(n=251)\end{array}$ & $\begin{array}{l}\text { Anti-MICA Fraco- } \\
\text { Positivo }(n=39)\end{array}$ & $\begin{array}{c}\text { Anti-MICA } \\
\text { Positivo }(n=49)\end{array}$ \\
\hline $\begin{array}{l}\text { Gênero Mascu- } \\
\quad \text { lino } n(\%)\end{array}$ & $182(53,7)$ & $23(59,0)$ & $27(55,1)$ \\
\hline Idade anos+DP & $44,1 \pm 12,8^{*}$ & $42,6 \pm 11,3$ & $36,9 \pm 12,0^{*}$ \\
\hline $\begin{array}{c}\text { Re-transplante } \\
n(\%)\end{array}$ & $19(7,6)^{\star \star}$ & $4(10,3)$ & $10(20,4)^{\star \star}$ \\
\hline $\begin{array}{c}\text { PRA-ELISA + } \\
n(\%)\end{array}$ & $29(11,6)$ & $7(18,0)$ & $10(20,4)$ \\
\hline $\begin{array}{l}\text { Hipersensibili- } \\
\text { zados\# n (\%) }\end{array}$ & $14(5,6)$ & $3(7,7)$ & $6(12,2)$ \\
\hline $\begin{array}{c}\text { Transplante } \\
\text { Combinado } \\
n(\%)\end{array}$ & $21(8,4)$ & $4(10,3)$ & $4(8,2)$ \\
\hline
\end{tabular}

$D P$ : desvio-padrão;

${ }^{*} P=0,00$

${ }^{\star *} P=0,01$, OR=3,1 [1,4-7,2];

\# PRA $>75 \%$ dos antígenos HLA de classe I testados em painel por citometria de fluxo.

Figura 1. Sobrevida atuarial do enxerto em receptores de primeiro transplante renal, conforme a presença de anticorpos anti-MICA pré-formados.

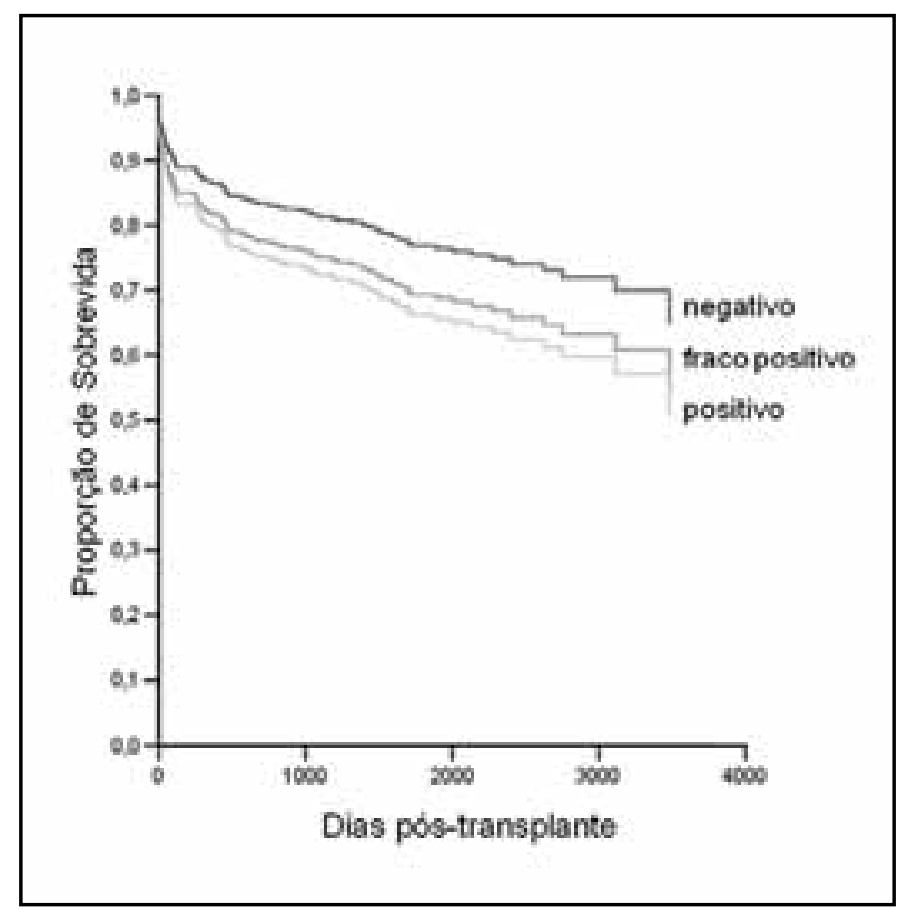

dificultou a análise da sobrevida, quando foram divididos entre os grupos conforme o padrão de anticorpos anti-MICA. A Tabela 4 apresenta a comparação do efeito dos níveis de anticorpos antiMICA na sobrevida do enxerto renal. 
Tabela 3. Descrição do esquema inicial de imunossupressão entre receptores de transplante renal, conforme a presença de anticorpos antiMICA pré-formados.

\begin{tabular}{|c|c|c|c|c|}
\hline $\begin{array}{c}\text { Imunossupressão } \\
\text { Inicial }\end{array}$ & $\begin{array}{c}\text { Anti-MICA } \\
\text { Negativo } \\
(\mathrm{n}=251)\end{array}$ & $\begin{array}{c}\text { Anti-MICA } \\
\text { Fraco - } \\
\text { Positivo } \\
(n=39)\end{array}$ & $\begin{array}{c}\text { Anti-MICA } \\
\text { Positivo } \\
(\mathrm{n}=49)\end{array}$ & $\begin{array}{c}\text { Total } \\
\mathrm{N}=339 \\
\mathrm{n}(\%)\end{array}$ \\
\hline \multicolumn{5}{|l|}{$\begin{array}{l}\text { Terapia de } \\
\text { Indução** }\end{array}$} \\
\hline$n(\%)$ & $111(44,2)$ & $18(46,2)$ & $18(36,7)$ & $147(43,4)$ \\
\hline \multicolumn{5}{|l|}{$\begin{array}{l}\text { Imunossupressão } \\
\text { Inicial }^{* *}(\mathrm{n})\end{array}$} \\
\hline CyA-Aza-Pred & 87 & 16 & 27 & $130(38,3)$ \\
\hline CyA-MMF-Pred & 82 & 10 & 6 & $98(28,9)$ \\
\hline FK-MMF-Pred & 40 & 4 & 9 & $53(15,6)$ \\
\hline FK-Rapa-Pred & 14 & 4 & 4 & $22(6,5)$ \\
\hline FK-Aza-Pred & 10 & 1 & 2 & $13(3,8)$ \\
\hline Outros & 18 & 4 & 1 & $23(6,8)$ \\
\hline
\end{tabular}

*terapia de indução: basiliximab, daclizumab ou anticorpo monoclonal anti-CD3

**Imunossupressão inicial:

CyA: ciclosporina

Aza: azatioprina

Pred: prednisona

MMF: micofenolato mofetil

FK: tacrolimo

Rapa: rapamicina

Outros: outras combinações, sempre incluindo MMF. FK elou Rapa

\section{DISCUSSÃO}

Apesar de há muito se estudar HLA e de muito recentemente se resgatar a importância dos fenômenos humorais sub-clínicos relacionados a esses aloantígenos, desde a década de 70 busca-se a identificação de outros antígenos de histocompatibilidade. . $^{3,4,9,10,1}$ ${ }^{1}$ Essa busca foi principalmente motivada pela observação de que rejeições agudas e hiperagudas também ocorrem, embora muito menos freqüentemente, em transplantes realizados entre pares de doadores e receptores HLA idênticos. ${ }^{17}$ As primeiras observações comprovaram que o principal sistema envolvido em rejeições era, de fato, o sistema HLA (corroborando seu próprio nome - "complexo principal de histocompatibilidade"), mas que existiam outros sistemas antigênicos também polimórficos chamados "secundários" ${ }^{16}$ Estudos recentes demonstram que 11 a $20 \%$ das perdas de enxerto ocorrem em pacientes que nunca desenvolveram anticorpos anti-HLA, sugerindo que antígenos não-HLA (especialmente MICA) possam estar relacionados a esse fenômeno. ${ }^{18}$

É recente a demonstração de que anticorpos anti-MICA podem ser formados a partir de processos imunizantes, como gestações e transplantes, e são mais freqüentemente encontrados em pacientes que perderam um enxerto renal do que em pacientes com o enxerto funcionante. ${ }^{18}$ Corroborando estes dados, o presente estudo demonstrou que em nosso meio, os $26 \%$ dos pacientes que foram submetidos a um transplante de rim na vigência de anticorpos antiMICA pré-formados eram mais freqüentemente receptores de retransplante. Embora os portadores de anticorpos anti-MICA tenham sido previamente imunizados pelo órgão transplantado, a triagem
Tabela 4. Comparação do efeito dos níveis de anticorpos anti-MICA préformados na sobrevida do enxerto renal.

\begin{tabular}{|c|c|c|c|c|}
\hline $\begin{array}{l}\text { Anticorpos } \\
\text { Anti-MICA }\end{array}$ & $\mathrm{n}$ & $\mathrm{HR}^{*}$ & IC (95\%) & $\mathbf{P}$ \\
\hline \multicolumn{5}{|c|}{$1^{\circ}$ Transplante } \\
\hline Neg & 232 & 1 & & \\
\hline $\mathrm{FP}$ & 35 & 1,4 & $0,8-2,7$ & 0,24 \\
\hline Pos & 39 & 1,6 & $0,8-3,0$ & 0,19 \\
\hline \multicolumn{5}{|l|}{ Ptrend $=0,09$} \\
\hline \multicolumn{5}{|c|}{ Re-Transplante } \\
\hline $\mathrm{Neg}$ & 19 & 1 & & \\
\hline $\mathrm{FP}$ & 4 & 0,8 & $0,1-4,5$ & 0,80 \\
\hline Pos & 10 & 0,7 & $0,2-2,7$ & 0,57 \\
\hline
\end{tabular}

${ }^{*} H R$ : Hazard Ratio obtidos em modelo de Cox-Regression, incluindo os seguintes fatores: idade, gênero, resultado de PRA, uso de terapia de indução e imunossupressão inicial incluindo drogas de segunda ou terceira geração Ptrend: $P$ de tendência linear.

através do PRA para anti-HLA de classe I não foi capaz de rastreá-los, chamando a atenção para a independência dos dois sistemas. ${ }^{19}$

Fato relevante é a observação de que diferentes centros identificam prevalências distintas de anticorpos anti-MICA. Isto certamente deriva das características genotípicas de cada grupo populacional e do painel de antígenos MICA testados. ${ }^{18}$ No presente estudo, as especificidades mais freqüentemente detectadas dos aloanticorpos foram $* 009$, *027 e *019. Todavia, analisando-se a freqüência genotípica determinada em estudo realizado na cidade de São Paulo, observa-se que os alelos mais frequentes em nossa população são, respectivamente, ${ }^{*} 008, * 002$ e $* 004 .{ }^{20}$ Destes, somente os dois últimos estavam incluídos no painel de antígenos analisados, estando o teste para *008 mascarado pela avaliação de anticorpos dirigidos contra o antígeno traduzido pelo alelo *027. Isto porque os alelos *008 e*027 diferem entre si apenas pelas suas respectivas sequências trans-membrana, não diferindo no seu potencial antigênico. ${ }^{21}$

Nesta população brasileira estudada constituída por 339 receptores de transplante renal de doador falecido, a presença de anticorpos anti-MICA pré-transplante não comprometeu a sobrevida do enxerto de forma significativa. Entretanto, a sobrevida de cerca de $70 \%$ em quatro anos entre pacientes com anticorpos antiMICA pré-formados e de $82 \%$ para aqueles sem esses anticorpos é semelhante aos dados prospectivos publicados por Terasaki e colaboradores em 2007. O estudo multicêntrico conduzido por esses autores demonstrou alta significância estatística, comparando a sobrevida do enxerto entre pacientes com anticorpos anti-MICA detectados após transplante (pré-formados ou de novo) e os que permaneceram sem aloanticorpos (anti-HLA/MICA) até o quarto ano pós-transplante ( $72 \% \times$ x $82 \%){ }^{22}$

É importante considerar que na série aqui estudada de pacientes, receptores com anticorpos anti-MICA fortemente positivos receberam esquemas imunossupressores menos potentes do que os receptores sem esse fator. Obviamente, isso não foi observado entre receptores de re-transplante. Nestes últimos, provavelmente a presença de fatores de risco mais relevantes, como a presença de 
anticorpos anti-HLA, parcialmente controlada pela utilização de um esquema inicial de imunossupressão mais potente, tenha mascarado um eventual efeito deletério adicional. Isto sugere que, existindo benefício no rastreamento de anticorpos anti-MICA, seu efeito não terá impacto tão grande quanto os fatores de risco já conhecidos (re-transplante e anticorpos anti-HLA).

Por outro lado, um efeito deletério na sobrevida do enxerto renal a partir dos resultados apresentados não pode ser excluído entre receptores de um primeiro enxerto. Este dado pode ser ainda mais valorizado diante da tendência à linearidade do efeito dos níveis de anticorpos anti-MICA pré-formados na sobrevida do enxerto em longo prazo. Esses resultados são extremamente importantes para a otimização das estratégias profiláticas e terapêuticas aplicáveis na maioria dos transplantes renais realizados em nosso meio, e são corroborados por sua contemporaneidade com estudos multicêntricos contundentes.
Análises de sobrevida atuarial do enxerto recentemente publicadas indicam resultados significativos do envolvimento de anticorpos anti-MICA como fator deletério em longo prazo. ${ }^{22-24}$ Isto deve fortalecer a busca da identificação desse efeito em nossa população, como possibilidade de atuação diferenciada no manejo de pacientes recebendo primeiro transplante.

\section{CONCLUSÃO}

Concluímos que a prevalência de anticorpos anti-MICA préformados em receptores de transplante renal proveniente de doador falecido foi da ordem de $26 \%$, mais freqüente entre receptores de re-transplante. O efeito deletério desses anticorpos pré-formados na sobrevida do enxerto renal não pode ser excluído entre receptores de um primeiro enxerto, necessitando estudos com maior número de pacientes.

\section{ABSTRACT}

Introduction: Anti-HLA preformed or developed antibodies after transplantation are associated to a lower graft survival. It has yet to be further studied if anti-MICA alloantibodies have the same deleterious effect. Purpose: To determine the anti-MICA antibodies prevalence among deceased kidney transplant recipients, and to analyze their effect on graft survival. Patients and Methods: 339 deceased kidney transplants were studied, all of them performed after a negative crossmatch against B and T+AHG lymphocytes. Anti-MICA analysis was performed using Luminex technology, and the sera were classified: negative (Neg , $n=251 ; 74 \%$ ), weak-positive (WP, $n=39 ; 11.5 \%$ ), and positive (Pos , $n=49 ; 14.5 \%$ ). Patient and transplant characteristics were compared, depending on the anti-MICA sera status (Ki-square, Fisher exact, t Student, Mann-Whitney). Graft survival was analyzed based on a Cox-Regression model which included: age, gender, PRA class-I pre-transplant test, induction therapy, initial immunosuppression with MMF, FK and/or rapamicine, and re-transplant (P<0.05 and CI95\%). Results: The preformed anti-MICA antibodies prevalence was $26 \%(\mathrm{n}=88)$. Anti-MICA-positive patients were younger (36.9+12.0 $\mathrm{x} 44.1+12.8$ years old; $\mathrm{P}=0.00)$, receiving more frequently a second or third graft $(20.4 \% \mathrm{x} 7.6 \%$, $\mathrm{P}=0.01)$. The anti-MICA status did not attain a statistical significance to the graft survival ( $\mathrm{Neg}: \mathrm{HR}=1 ; \mathrm{WP}: \mathrm{HR}=0.7, \mathrm{P}=0.25$; Pos $: \mathrm{HR}=0.94, \mathrm{P}=0.88$ ). A deleterious effect might not be excluded among the first graft recipients (WP:HR=1.4[0.8-2.7], $\mathrm{P}=0.28$, and $\mathrm{Pos}: \mathrm{HR}=1.6[0.9-3.1], \mathrm{P}=0.14$ ), with a $\mathrm{Ptrend}=0.09$ for the antibody levels. Conclusion: The anti-MICA antibodies prevalence upon deceased kidney transplant was $26 \%$, more frequent among young patients receiving a re-graft. A deleterious effect among recipients of first graft might not be excluded. Further studies are needed with a major sampling.

Keywords: Antibodies, Mica, Kidney Transplantation, Graft Survival.

\section{REFERÊNCIAS}

1. Terasaki PI \& McLelland JD. Microdroplet assay of human serum cytotoxins. Nature. 1964;204:998-1000

2. Abbud Filho M, Pestana JOM, Garcia VD: Agentes imunossupressores químicos. In: Garcia, Abbud Filho, Neumann e Medina Pestana. Transplante de Órgãos e Tecidos, Segmentofarma Ed., São Paulo, 2006

3. Crespo M, Pascual M, Tolkoff-Rubin N, Mauiyyedi S, Collins AB, Fitzpatrick D, et al. Acute humoral rejection in renal allograft recipients: I. incidence, serology and clinical characteristics. Transplantation. 2001;71(5):652-8

4. Mauiyyedi S, Crespo M, Collins AB, Schnneeberger EE, Pascual MA, Saidman SL, et al. Acute Humoral Rejection in Kidney Transplantation: II. Morphology, Immunopathology, and Pathologic Classification. J Am Soc Nephrol. 2002;13(3):779-87

5. Mauiyyedi S, Pelle PD, Saidman S, Collins AB, Pascual M, Tolkoff-Rubin NE, et al. Chronic humoral rejection: identification of antibody-mediated chronic renal allograft rejection by C4d deposits in peritubular cappilaries. J Am Soc Nephrol. 2001;12(3):574-82
6. Montgomery RA, Zachary AA, Racusen LC, Leffel MS, King KE, Burdick $\mathrm{J}$, et al. Plasmapheresis and intravenous immune globuin provides effective rescue therapy for refractory humoral rejection and allows kidneys to be successfully transplanted into cross-match-positive recipients. Transplantion. 2000;70(6):887-95

7. Feucht HE, Schneeberger H, Hillebrand G, Burkhardt K, Weiss M, Riethmuller G, et al. Cappilary deposition of C4d complement fragment and early renal graft loss. Kidney Int. 1993;43:1333-8

8. Feucht HE, Lederer SR \& Kluth B. Humoral Alloreactivity in recipients of renal allografts as a risk factor for the development of delayed graft function. Transplantation. 1998;65(5):757-8

9. Mauiyyedi S \& Colvin RB. Humoral rejection in kidney transplantation: new concepts in diagnosis and treatment. Curr Opin Nephrol Hypertens. 2002;11(6):609-18

10. Michelon T, Schroeder R, Fagundes I, Canabarro R, Sporleder H, Rodrigues H et al: Relevância clínica de baixos títulos de aloanticorpos preformados detectados em prova cruzada somente por citometria de fluxo no pré-transplante renal. J Bras Transpl. 2005;8(3):364-71 
11. Terasaki PI \& Ozawa M. Predicting kidney graft failure by HLA antibodies: a prospective trial. Am J Transplant. 2004;4(3):438-43

12. Deboni L, Sporleder H, Fernandes S, Keitel E, Bittar AE, Garcia V, Neumann J. Kidney allograft outcome analyzed by donor-reactive antibodies after transplantation. Transplant Proc. 1995;27(2):1823-4

13. Stephens AHF. MICA and MICB genes: can the enigma of their polymorphism be resolved? Trends Immunol. 2001;22(7):378-85

14. Molinero LL, Marcos CY, Mirbaha F, Fainboim L, Stastny P, Zwirner NW. Codominant expression of the polymorphic MICA antigens encoded by genes in the HLA region. Eur J Immunogen. 2002;29:315-9

15. Stastny P. Introduction: MICA/MICB in Innate Immunity, Adaptative Immunity, Autoimmunity, Cancer, and in the immune response to transplants. Human Immunology. 2006;67:141-4

16. Collins RWM. Human MHC class I Chain Related (MIC) genes: their biological function and relevance to disease and transplantation. Eur J Immunogen. 2004;31:105-14

17. Kalil J, Guillerme L, Neumann J, Rosales C, Marin M, Saldanha L, et al. Humora rejection in two HLA identical living related donor kidney transplants. Transplant Proc. 1989;21(1):711-3
18. Zou Y, Statsny P, Süsal C, Döhler B, Opelz G. Antibodies against MICA antigens and kidney-transplant rejection. N Engl J Med. 2007;357:1293-300

19. Bahram S. MIC genes: from genetics to biology. Adv Immunol. 2000;76:1-60

20. Marin MLC \& Goldberg AC. Novas fronteiras nos estudos de associações com doenças In Porto LCMS \& Pontes LFS. Estudos de associação HLA x Doenças: Extratos do I Simpósio Brasileiro. Ed UERJ, Rio de Janeiro, 2007

21. Zhang Y, Lazaro AM, Zou Y, Lavingia B, Moraes EM, Moraes RJ, Stastny P. MICA polymorphism in south american indian. Immunogenetics. 2002;53:900-6

22. Terasaki PI, Ozawa M \& Castro R. Four-year follow-up of a prospective trial of HLA and MICA antibodies on kidney graft survival. Am J Transpl. 2007;7:408-15

23. Mizutani K, Terasaki P, Bignon JD, Hourmant M, Cesbron-Gautier A, Shih RNJ, et al. Association of kidney transplant failure and antibodies against MICA. Human Immunol. 2006;67:683-91

24. Mizutani K, Terasaki P, Rosen A, Esquenazi V, Miller J, Shih RNJ, et al. Serial tenyear follow-up of HLA and MICA antibody production prior to kidney graft failure. Am J Transpl. 2005;5:2265-72 